\title{
The Endocyclic Carbon Substituent of Guanidinate and Amidinate Precursors Controlling ALD of InN Films
}

Polla Rouf, Nathan J O'Brien, Karl Rönnby, Rouzbeh Samii, Ivan G. Ivanov, Lars Ojamäe, Henrik Pedersen Submitted date: 19/06/2019 - Posted date: 19/06/2019

Licence: CC BY-NC-ND 4.0

Citation information: Rouf, Polla; O'Brien, Nathan J; Rönnby, Karl; Samii, Rouzbeh; Ivanov, Ivan G.; Ojamäe, Lars; et al. (2019): The Endocyclic Carbon Substituent of Guanidinate and Amidinate Precursors Controlling ALD of InN Films. ChemRxiv. Preprint.

Indium nitride $(\mathrm{InN})$ is an interesting material for future high frequency electronics, due to its high electron mobility. The problematic deposition of InN films currently prevents full exploration of InN based electronics. We present studies of atomic layer deposition (ALD) of InN using In precursors with bidentate ligands forming In-N bonds; tris(N,N-dimethyl-N',N"'-diisoproprylguanidinato)indium(III), tris(N,N'-diisopropylamidinato)indium(III) and tris(N,N'-diisopropylformamidinato)indium(III). These compounds form a series were the size of the substituent in the endocyclic position decreases from $-\mathrm{NMe}_{2}$, to $-\mathrm{Me}$ and to $-\mathrm{H}$, respectively. We show that when the size of the substituent decreases, InN films with higher crystalline- and optical quality, lower roughness and an $\mathrm{In} / \mathrm{N}$ ratio closer to unity is achieved. From quantum chemical calculations we show that the smaller substituents lead to less steric repulsion and weaker bonds between the ligand and In centre. We propose that these effects render a more favoured surface chemistry for the nitidisation step in the ALD cycle which explains the improved film properties.

File list (2)

Submitted Manuscript.pdf (904.49 KiB)

view on ChemRxiv - download file 


\title{
The endocyclic carbon substituent of guanidinate and amidinate precursors controlling ALD of InN films
}

Polla Rouf*, Nathan J. O’Brien, Karl Rönnby, Rouzbeh Samii, Ivan G. Ivanov, Lars Ojamäe, Henrik Pedersen

Department of Physics, Chemistry and Biology, Linköping University, SE-581 83 Linköping, Sweden

*Corresponding author, e-mail: polla.rouf@liu.se

\begin{abstract}
Indium nitride $(\mathrm{InN})$ is an interesting material for future high frequency electronics, due to its high electron mobility. The problematic deposition of InN films currently prevents full exploration of InN based electronics. We present studies of atomic layer deposition (ALD) of InN using In precursors with bidentate ligands forming In-N bonds; $\operatorname{tris}(N, N$-dimethyl- $N$ ',$N$ ' 'diisoproprylguanidinato)indium(III), $\quad \operatorname{tris}(N, N$ '-diisopropylamidinato)indium(III) and $\operatorname{tris}\left(N, N^{\prime}\right.$-diisopropylformamidinato)indium(III). These compounds form a series were the size of the substituent in the endocyclic position decreases from $-\mathrm{NMe}_{2}$, to $-\mathrm{Me}$ and to $-\mathrm{H}$, respectively. We show that when the size of the substituent decreases, InN films with higher crystalline- and optical quality, lower roughness and an $\mathrm{In} / \mathrm{N}$ ratio closer to unity is achieved. From quantum chemical calculations we show that the smaller substituents lead to less steric repulsion and weaker bonds between the ligand and In centre. We propose that these effects render a more favoured surface chemistry for the nitidisation step in the ALD cycle which explains the improved film properties.
\end{abstract}

\section{Introduction}

The high electron saturation velocity, small effective electron mass and high electron mobility of indium nitride ( $\mathrm{InN}$ ) makes it a suitable material for high frequency electronics. ${ }^{1,2,3}$ The possibility to integrate $\mathrm{InN}$ in existing high electron mobility transistors (HEMTs), currently based on other group 13 nitrides - aluminum nitride (AIN), gallium nitride $(\mathrm{GaN})$ and their alloys, makes InN a key material for future high frequency transistors. However, InN decomposes to In metal and $\mathrm{N}_{2}$ gas at around $500{ }^{\circ} \mathrm{C},{ }^{4}$ making deposition of $\mathrm{InN}$ films challenging with conventional methods. Chemical vapor deposition (CVD) routes to InN typically use trimethyl indium $\left(\operatorname{In}\left(\mathrm{CH}_{3}\right)_{3}\right)$ and ammonia $\left(\mathrm{NH}_{3}\right)$ as precursors. The low upper temperature tolerated by the $\mathrm{InN}$ crystal and the poor thermal reactivity of $\mathrm{NH}_{3}$ forces $\mathrm{InN} C V D$ to use $\mathrm{NH}_{3} / \mathrm{In}\left(\mathrm{CH}_{3}\right)_{3}$ in ratios in the order of $100,000,{ }^{5,6}$ Rather than relying on gas phase 
reactivity to form more reactive species, a surface controlled CVD approach with time-resolved precursor delivery could be an alternative way to eliminate the high N/In precursor ratios. This approach would rely on surface chemical reactions between gas phase species and chemisorbed surface moieties. If self-limiting surface chemistry is achieved, such an approach would be an atomic layer deposition (ALD) process. ALD of $\operatorname{InN}$ has been demonstrated using $\operatorname{In}\left(\mathrm{CH}_{3}\right)_{3}$ and $\mathrm{N}_{2}$ plasma $^{7,8}$ or $\mathrm{NH}_{3}$ plasma ${ }^{9}$, affording $\mathrm{InN}$ of high crystalline quality, albeit with significant levels of carbon impurities emanating from the $\mathrm{In}-\mathrm{C}$ bonds in the $\operatorname{In}\left(\mathrm{CH}_{3}\right)_{3}$ precursor. Low temperature ALD processes based on precursors with metal-carbon bonds are known to render carbon impurities in the few atomic percent range. ${ }^{10}$ It has further been shown that plasma ALD of $\mathrm{InN}$ requires very long plasma exposures (on the order of $100 \mathrm{~s}$ ) to reduce the carbon content down to approximately 3 atomic percent. ${ }^{8}$ This motivates the use of alternative In-precursors without In-C bonds or oxygen atoms as constituents. Herein, we explore homoleptic hexacoordinated In(III) precursors with In-N bonded bidentate ligands for ALD of InN. These molecules - $\operatorname{tris}(N, N$-dimethyl- $N$ ', $N$ ' '-diisoproprylguanidinato)indium(III) (1), $\operatorname{tris}(N, N$ 'diisopropylamidinato)indium(III) (2) and tris( $N, N$ '-diisopropylformamidinato)indium(III) (3) (Figure 1), have all been recently reported as In precursors for ALD of $\operatorname{In}_{2} \mathrm{O}_{3}{ }^{11,12,13,14,15} \mathrm{We}$ show that the size of the substituent on the endocyclic carbon atom in the ligand backbone has a substantial effect on the film deposition, with the smaller substituents affording films of higher crystalline quality, smoother morphology, lower impurity levels in the deposited InN films and optical properties closer to those reported for bulk $\mathrm{InN}$. We suggest that this is explained by improved surface chemistry when the size of the substituent is reduced.

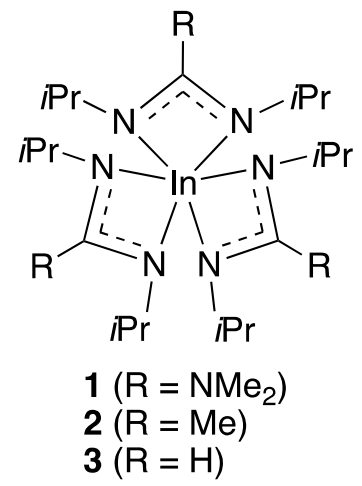

Figure 1: Hexacoordinated In (III) precursors 1-3 used for the ALD study of InN. 


\section{Methods}

Film deposition

Film deposition was undertaken in a hot-wall ALD system, Picosun R-200, equipped with a Litmas Remote Inductively Coupled Plasma Source operating at a base pressure of $400 \mathrm{~Pa}$ with a continuous flow of $\mathrm{N}_{2}$ (99.999\% and further purified with a getter filter to remove moisture) into the reaction chamber. The films were deposited on $\mathrm{Si}$ (100) substrates that were cut into approximately $15 \times 15 \mathrm{~mm}$ pieces. The substrates were loaded into the chamber without a loadlock chamber and placed onto a heated substrate holder. After loading the substrates, the chamber was baked for 2 hours at $450{ }^{\circ} \mathrm{C}$ with a continuous $\mathrm{N}_{2}$ flow $(300 \mathrm{sccm})$ to minimize

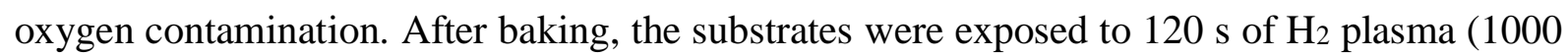
W plasma power using a gas mixture of $100 \mathrm{sccm}$ Ar and $10 \mathrm{sccm} \mathrm{H}_{2}$ ) followed by $120 \mathrm{~s} \mathrm{~N}_{2}$ plasma (2800 W plasma power using a gas mixture of $80 \mathrm{sccm} \mathrm{Ar}$ and $380 \mathrm{sccm} \mathrm{N_{2 }}$ ) to further remove oxygen and moisture, parts of the native silicon oxide as well as to nitridise the substrate surface. Precursors 1-3 were loaded into a glass vial and placed in a heated stainless-steel bubbler without a dip-tube for the incoming carrier gas. Approximately $0.5 \mathrm{~g}$ of precursor was used for 500 ALD cycles. The bubbler temperature was set to 160,190 and $155^{\circ} \mathrm{C}$ for $\mathbf{1}, 2$ and 3 , respectively. A flow of $\mathrm{N}_{2}$ carrier gas was used through the bubbler as the temperature alone was not enough to obtain a sufficient vapor pressure to move the precursor into the reaction chamber. Thermal decomposition of $\mathbf{1}$ limited the bubbler temperature. A bubbler temperature of $160{ }^{\circ} \mathrm{C}$ for 1 is not optimal as it starts to decompose at $120{ }^{\circ} \mathrm{C}^{14}$, but lower temperatures did not afford film deposition due to insufficient vapor pressure. To circumvent the low vapor pressures of $\mathbf{1}$ and 2, a fill-empty approach was employed. This approach has been previously reported $^{9}$, in brief it uses several pulses of In-precursor with first a high, then low flow of carrier gas into the bubbler. This creates a larger pressure gradient between the bubbler and the reaction chamber, which facilitates the movement of the precursor into the reaction chamber. For 1, 2 pulses were required using the fill-empty process (Table S1). The same fill-empty process was used for 2 , but 5 pulse cycles was required to obtain film deposition, indicative of the slow surface chemistry previously discussed for $2 .{ }^{12}$ The fill-empty process was not required for $\mathbf{3}$, however, 3 pulses were required to obtain full surface coverage, again indicative of a slow surface chemistry as previously discussed. ${ }^{12}$ The nitrogen source for the film depositions was an $\mathrm{Ar} / \mathrm{NH}_{3}(100 / 75 \mathrm{sccm})$ gas mixture, which was ignited with a plasma power of $2800 \mathrm{~W}$ for $9 \mathrm{~s}$ and followed by a $10 \mathrm{~s}$ purge. The same plasma parameters were used for all the In precursors unless otherwise stated. 


\section{Precursor synthesis}

Precursor 1, 2 and $\mathbf{3}$ were prepared according to the literature procedures (Scheme 1). ${ }^{11,12,13}$ All manipulations were carried out under a nitrogen atmosphere using standard Schlenk and glovebox techniques. All NMR spectra were measured with Oxford Varian $300 \mathrm{MHz}$ spectrometer. Solvents peaks were used as an internal standard for the ${ }^{1} \mathrm{H}$ NMR (300 MHz) spectra. All anhydrous solvents were purchased from Sigma-Aldrich ${ }^{\mathrm{TM}}$ and further dried with molecular sieves $4 \AA$. $\mathrm{InCl}_{3}$ (anhydrous, 99.99\%) was purchased from Sigma-Aldrich ${ }^{\mathrm{TM}}$ and used without further purification. Precursor $\mathbf{1}$ and $\mathbf{2}$ were purified by recrystallization from hexanes and 3 by sublimation $\left(90{ }^{\circ} \mathrm{C}\right.$ at 0.1 mbar). Previously reported thermogravimetric analysis of $\mathbf{1}, \mathbf{2}$, and $\mathbf{3}$ showed single step evaporations with onset temperature and residual masses of $175{ }^{\circ} \mathrm{C} / 11.5 \%{ }^{14}, 240{ }^{\circ} \mathrm{C} / 0 \%{ }^{12}$ and $200{ }^{\circ} \mathrm{C} / 0 \%{ }^{12}$, respectively.

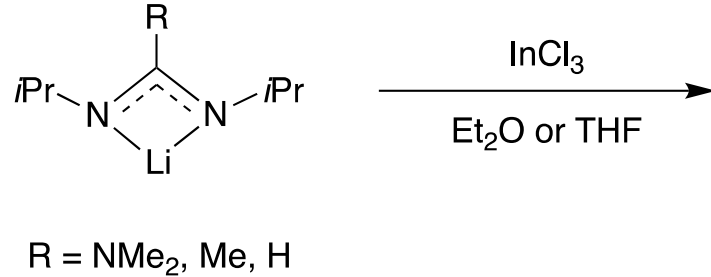

Scheme 1. Synthesis of hexacoordinated In (III) precursors 1-3.

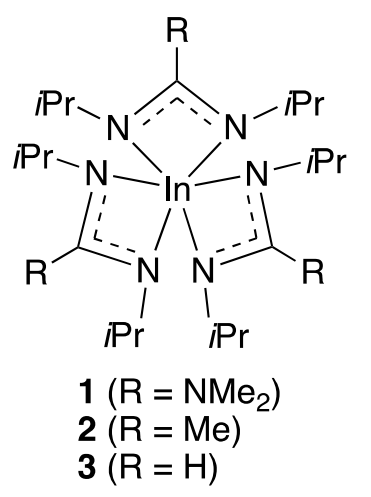

\section{Film characterization}

The crystallinity of deposited films was studied using Grazing Incidence X-ray diffraction (GIXRD) in a PANalytical EMPYREAN MRD XRD with a $\mathrm{Cu}$-anode $\mathrm{X}$-ray tube and 5-axis (x-y-z-v-u) sample stage. PANalytical X'Pert PRO with a Cu-anode tube and Bragg-Brentano HD optics was used for $\theta-2 \theta$ measurement and X-ray Reflectivity (XRR) mode to measure the thickness of the films. From the XRR measurements the software PANalytical X'Pert reflectivity was used to fit the data using a two-layer model, InN/substrate ( $\mathrm{Si}$ and GaN). A LEO 1550 Scanning electron microscopy (SEM) with an acceleration energy of 3-20 kV was used to characterize the morphology of the film. SEM was also used for film thickness measurements on cross section samples when the surface roughness made XRR measurements unreliable. The composition and chemical bonding of the atoms in the film was characterized with a Kratos AXIS Ultra DLD X-ray photoelectron spectroscopy (XPS) equipped with Ar $(0.30 \mathrm{eV})$ sputtering source. CasaXPS software was used to evaluate the data. Gaussian- 
Laurentius functions and Shirley background were used to fit the experimental XPS data. The Raman spectra were recorded on a micro-Raman setup utilizing 100X objective and 532-nm solid-state laser (Coherent, Sapphire SF 532-150). The laser was focused to $\sim 0.8 \mu \mathrm{m}$ spot on the sample. The power used was below $1 \mathrm{~mW}$ to avoid overheating of the sample. The Raman signal was dispersed by a monochromator (Jobin Yvon, HR460) coupled to a CCD camera. With the 1200 grooves/mm grating used in this measurement the resolution was about $3 \mathrm{~cm}^{-1}$. In order to obtain smooth enough spectra to distinguish the weak signal of the InN film from the strong signal of the substrate, 100 subsequent acquisitions by $20 \mathrm{~s}$ were acquired for each sample resulting in a total acquisition time of 2000 s per sample. No changes were observed in the spectra during the series indicating that the laser power utilized was sufficiently low to avoid thermal damage.

\section{Computational details}

Density functional theory (DFT) calculations were performed for both gas phase and surface reactions and structures. Gas phase calculations were carried out using the Gaussian16 software suite $^{16}$. Atomic structures where optimized and harmonic normal mode vibrations were calculated with B3LYP/def2TZVP level of theory together with the D3 version of Grimme's empirical dispersion ${ }^{17,18,19}$. All structures where verified to have no imaginary frequencies. Enthalpy and Gibbs free energy where calculated at STP (1 atm, 298.15 K). Surface calculations were carried out using the VASP software with optimizers extended by the VTST package. $^{20,21,22}$ The calculations were preformed using the generalized gradient approximation (GGA) functional PBE using with the D3 version of Grimme's empirical dispersion, Projector augmented wave (PAW) potentials and a cut-off energy of $700 \mathrm{eV} \cdot{ }^{23,24,25} \mathrm{~A}$ slab of consisting of $4 \mathrm{In}_{16} \mathrm{~N}_{16}$ layers with wurtzite (0001) orientation in a cell with dimensions 14.25, 12.34 and $40.40 \AA$ (Figure S1a) was made to model the surface. The lattice parameters where obtained by optimization of bulk lattice parameters and padded with vacuum along the c-direction to ensure separation of the slabs. Dangling bonds on the bottom of the slab was passivated by hydrogen with 0.75 charge and the top of the cell was saturated with $\mathrm{NH}_{2}$ groups, modelling a probable surface after the $\mathrm{NH}_{3}$ pulse. ${ }^{26}$ The slab was optimized with respect to all atomic positions. To model an adsorbed precursor, two hydrogens from neighboring $\mathrm{NH}_{2}$ were removed and a precursor molecule with two ligands removed was introduced above this site. The structures where then optimized with the 3 bottom layers of the slab frozen, Figure S1b-d shows the optimized structures. 


\section{Results and Discussion}

\section{ALD behaviour}

Film deposition experiments where the pulse time for $\mathbf{1}$ was varied showed that the deposition rate saturated at approximately $0.13 \AA$ /cycle for pulse times longer than $3.5 \mathrm{~s}$ (Figure 2a). This indicates a self-limiting surface chemistry between $\mathbf{1}$ and the $\mathrm{NH}_{3}$ plasma. As pointed out above, the bubbler temperature required for sufficient vapor pressure of $\mathbf{1}$ is higher than its decomposition point. Decomposition of $\mathbf{1}$ was observed in the bubbler by the formation of a metallic grey powder after the bubbler had been heated to $160{ }^{\circ} \mathrm{C}$ for approximately 9 hours. The ${ }^{1} \mathrm{H}-\mathrm{NMR}$ spectrum of the grey powder suspended in $\mathrm{C}_{6} \mathrm{D}_{6}$ showed the presence of the same unidentified thermolysis product as previously reported ${ }^{11}$ (Figure S2). The decomposition of 1 made it difficult to fully establish if saturation was due to self-limiting surface chemistry or limited by its low vapor pressure.

Reducing the size of the substituent on the carbon atom in the endocyclic position of the ligand from $-\mathrm{NMe}_{2}(\mathbf{1})$ to $-\mathrm{Me}(\mathbf{2})$ increased the volatility and thermal stability of the resulting In precursor. ${ }^{12}$ It has also been shown that $\mathbf{2}$ has slow surface reaction kinetics, which was mitigated by a stop-flow ALD process in the literature. ${ }^{12}$ As our ALD reactor does not have this feature, multiple pulses of $\mathbf{2}$ was used to compensate for the slow kinetics (See supporting information, Table S1). Different pulse sequences of 2 were investigated and the sequence shown in Table S1 was found to be most suited for deposition. It should be noted here that all five pulses of 2 were required to obtain $\mathrm{InN}$ film. The length of the last pulse was therefore changed in film deposition experiments where the pulse time of 2 was varied (Figure 2b). It was found that for pulse times longer than $1 \mathrm{~s}$, the growth per cycle (GPC) saturates at $0.97 \AA ̊$ /cycle, indicating a self-limiting surface chemistry. Figure $2 \mathrm{~b}$ also shows that $9 \mathrm{~s}$ of $\mathrm{NH}_{3}$ plasma was required to obtain saturated growth chemistry. The temperature dependence of the GPC for 2 shows a narrow plateau between 290-310 ${ }^{\circ} \mathrm{C}$ (Figure 2d), which indicates an unstable precursor or deposited monolayer at higher temperatures. XRR and cross section SEM analysis could not verify film thickness between $200-280{ }^{\circ} \mathrm{C}$ and $320-380{ }^{\circ} \mathrm{C}$ due to roughness and assumed low growth rate at these temperatures. At temperatures $\geq 320{ }^{\circ} \mathrm{C}, \mathbf{2}$ starts to decompose ${ }^{12}$ which could be an explanation to why the thickness decreases when the deposition temperature is increased. 
Decreasing the size of the endocyclic carbon substituent from $-\mathrm{Me}(\mathbf{2})$ to $-\mathrm{H}(\mathbf{3})$, has been shown to render an even more reactive and thermally stable In precursor. ${ }^{12}$ A stop flow process was still required for ALD of $\operatorname{In}_{2} \mathrm{O}_{3}$ using 3, indicating a slow surface reaction kinetics. ${ }^{12}$ Analogous to $\mathbf{2}$, multiple pulses of $\mathbf{3}$ was used to allow the precursor time to react with the surface (Table S1). It was found that 3 pulses were sufficient to obtain surface saturation on the substrate. All three pulses were varied, similarly to $\mathbf{2}$, only changes to the last pulse gave different film thicknesses. This again indicates that the last pulse is essential for saturation of the surface using this multiple pulse process. Figure 2c shows how the GPC is dependent on the pulse lengths of $\mathbf{3}$ and $\mathrm{NH}_{3}$ plasma. When no last pulse was used (X $=0$ in Table $\left.\mathrm{S} 1\right)$ the growth rate was $0.27 \AA$ /cycle. When the last pulse was added ( $\mathrm{X}=1 \mathrm{~s}$ ), the growth rate increased to $0.4 \AA$ /cycle and saturated at $0.4 \AA / \mathrm{s}$ for $\mathrm{X} \geq 1 \mathrm{~s}$ (Figure 2c). The saturation curve for $\mathrm{NH}_{3}$ plasma (Figure 2c) shows that at least $9 \mathrm{~s}$ of plasma exposure is necessary to saturate the GPC. These results indicate self-limiting surface chemistry for $\mathbf{3}$ and $\mathrm{NH}_{3}$ plasma. The dependence of temperature on the GPC (Figure 2e) shows a plateau between 200-280 ${ }^{\circ} \mathrm{C}$. Higher temperatures resulted in a lower GPC, which is most likely due to desorption of $\mathbf{3}$ from the surface. For all the saturation curves of $\mathbf{2}$ and $\mathbf{3}$, the reaction temperature was set at $300{ }^{\circ} \mathrm{C}$ and $250{ }^{\circ} \mathrm{C}$, respectively. Figure $2 \mathrm{f}$ shows the film thickness for deposition using 3 with a different number of ALD cycles. A linear dependence is observed; however, this trend could not be extrapolated to zero film thickness for zero ALD cycles. Instead, the trend line shows zero film thickness at 110 ALD cycles. This indicates a nucleation delay on Si (100) of approximately 110 ALD cycles. If the GPC is calculated considering the nucleation delay of 110 cycles, it would be $0.51 \AA$ A/cycle.

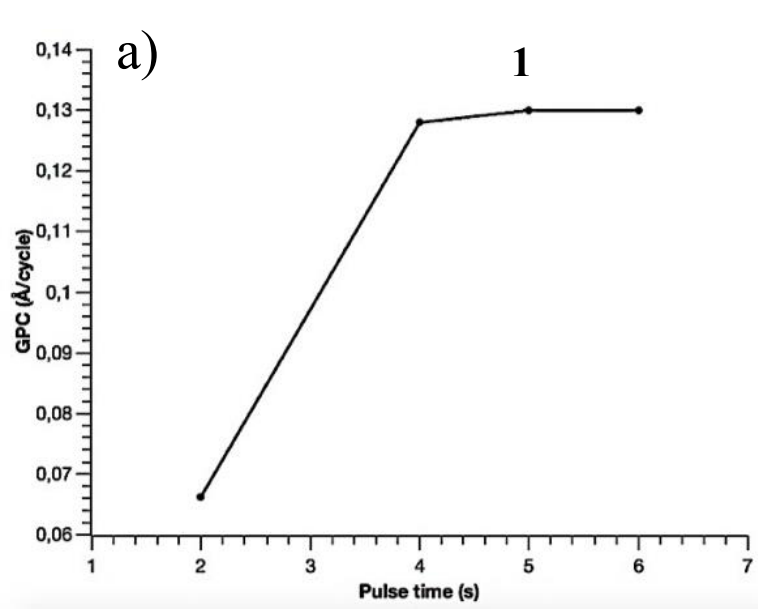

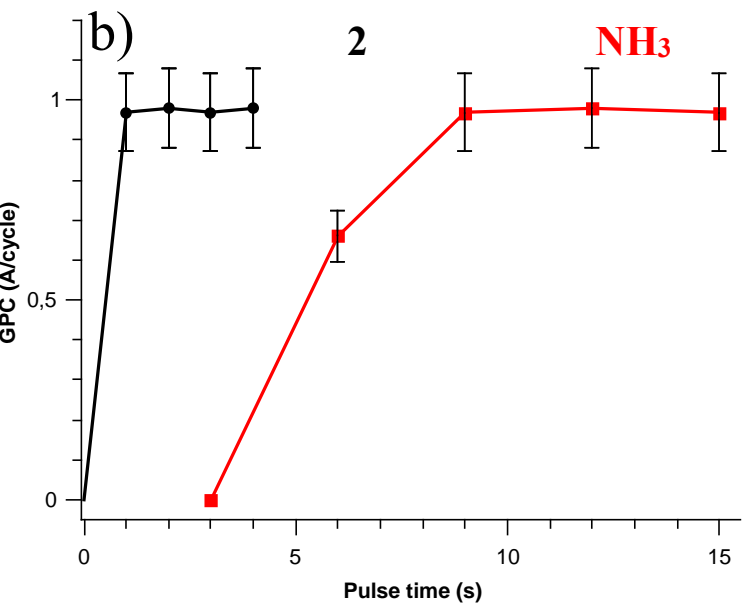

2 

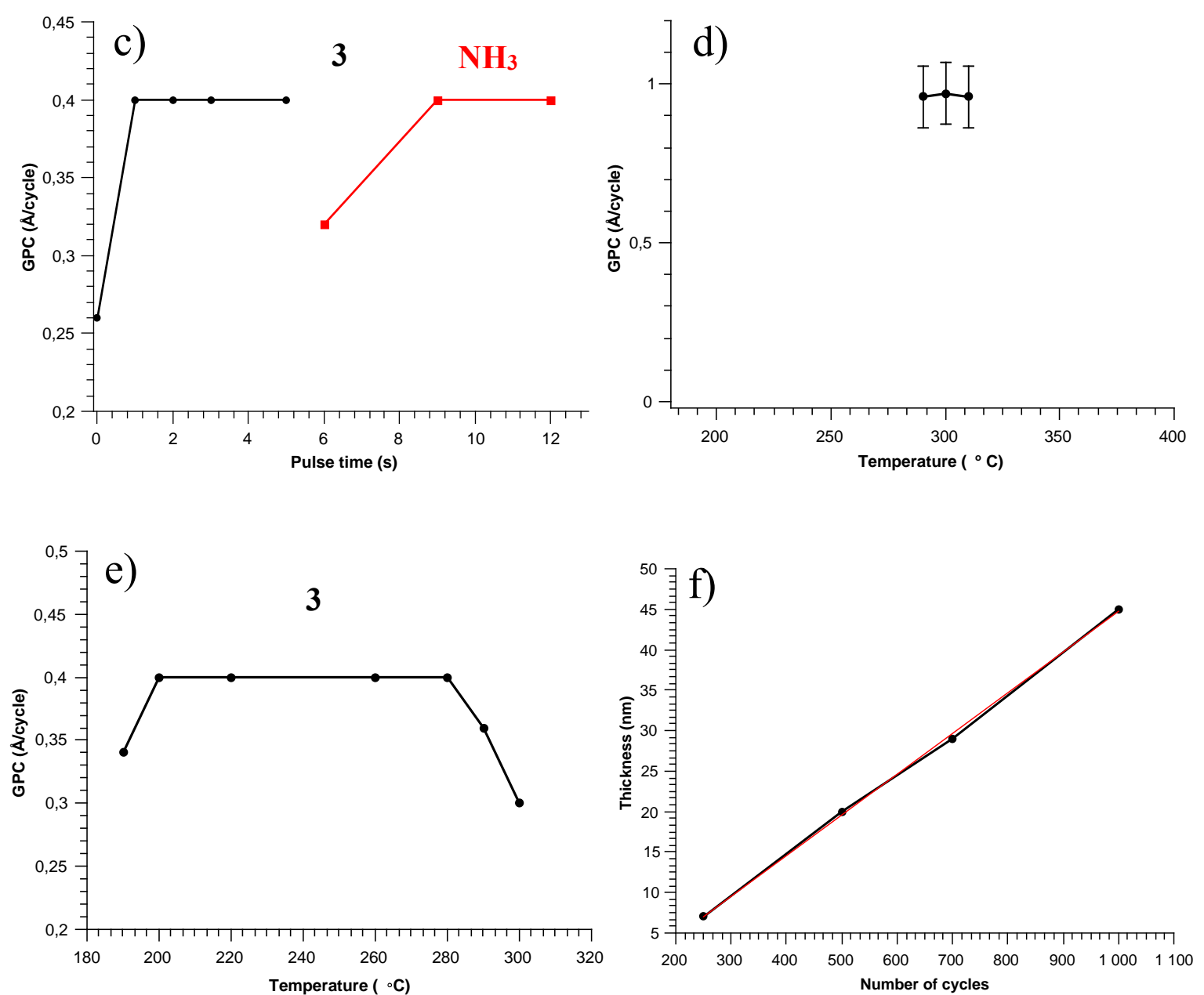

Figure 2. a) Saturation curve of 1 under constant conditions of a 13 s $\mathrm{NH}_{3}$ plasma pulse and deposition temperature of $200{ }^{\circ} \mathrm{C} . \mathrm{b}$ ) the growth per cycle of 2 with different $\mathrm{NH}_{3}$ plasma pulse times (red) and different pulse times of 2 (black line), both deposited at $300{ }^{\circ} \mathrm{C}$. c) the growth per cycle with different pulse times of 3 (last pulse was varied, " in Table S1) at $220^{\circ} \mathrm{C}$ with a $9 \mathrm{~s} \mathrm{NH}_{3}$ plasma pulse (black line) and the growth per cycle curve of 3 at different $\mathrm{NH}_{3}$ plasma pulses and with a 3, 2, 1 s pulse sequence of 3 at $220{ }^{\circ} \mathrm{C}$ (red line). d) the growth per cycle curve of 2 at different temperatures, with a $9 \mathrm{~s} \mathrm{NH}_{3}$ plasma pulse and the same pulse sequence of 2 as shown in Table S1. Note that XRR and cross section SEM analysis could not verify film thickness between $200-280{ }^{\circ} \mathrm{C}$ and $320-380^{\circ} \mathrm{C}$ due to roughness and assumed low growth rate at these temperatures. $e$ ) the growth per cycle curve of $\mathbf{3}$ at different temperatures with a 3,2, 1 s pulse sequence of $\mathbf{3}$ and a 9 s $\mathrm{NH}_{3}$ plasma pulse. f) The growth behaviour of 3 at $220{ }^{\circ} \mathrm{C}$ with number of cycles, with a $9 \mathrm{~s} \mathrm{NH}$ plasma pulse and same pulse sequence of 3 as shown in Table S1. The red line indicates the linear trend. 
Film crystallinity and morphology
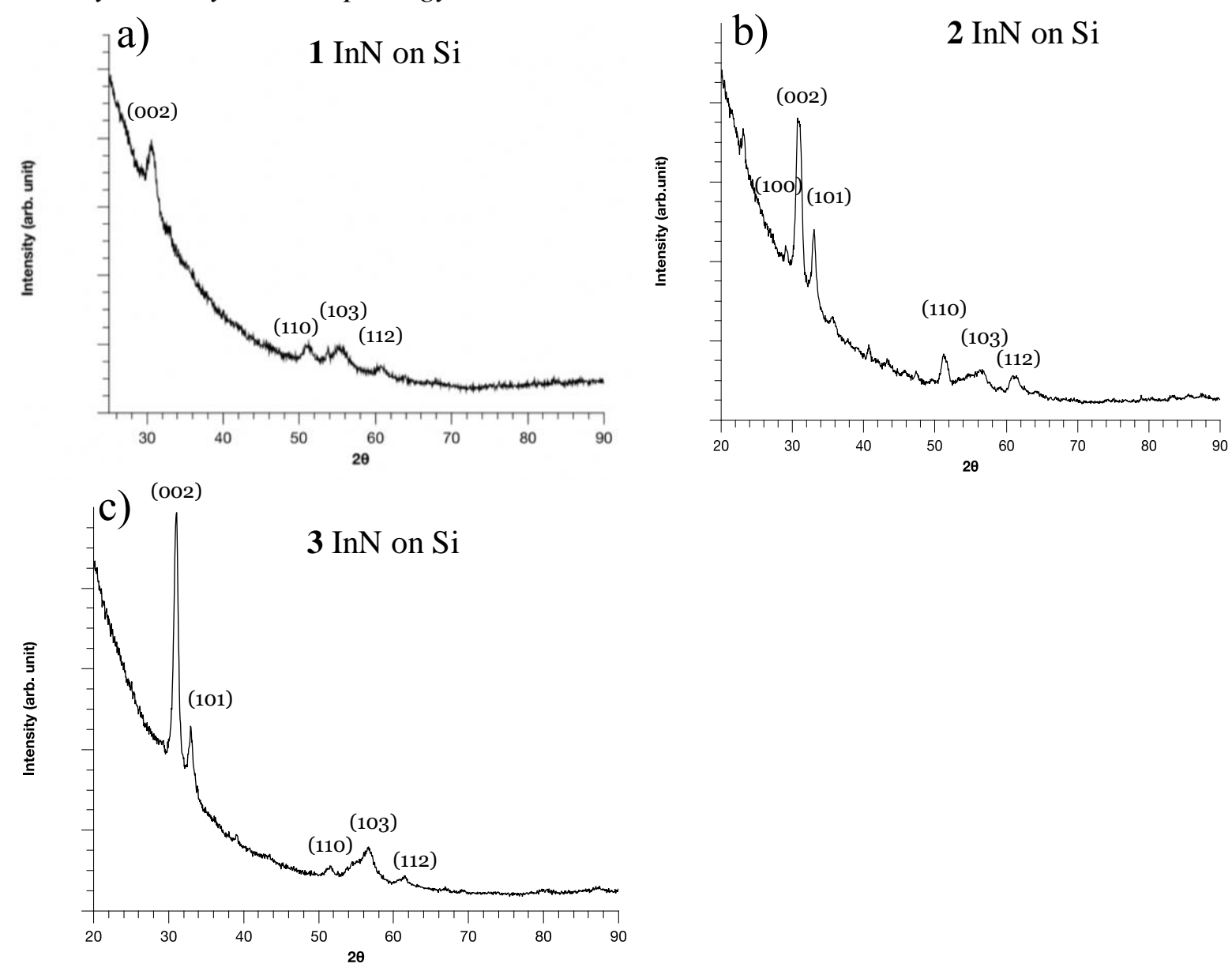

Figure 3. a) GIXRD of 1 on Si (100), $13 \mathrm{~s} \mathrm{NH}_{3}$ plasma pulse and $6 \mathrm{~s}$ pulse time of 1 deposited at $200{ }^{\circ} \mathrm{C}$, showing crystalline hexagonal InN. The FWHM of the (002) peak was $1.174^{\circ} \mathrm{b}$ ) GIXRD of 2 on Si (100), $9 \mathrm{~s} \mathrm{NH}_{3} \mathrm{plasma}$ pulse and same pulse sequence of 2 as shown in Table $S 2$ at $250{ }^{\circ} \mathrm{C}$, showing crystalline hexagonal InN with a preferred orientation along the c-axis. The FWHM of the (002) peak was 0.891 ${ }^{\circ} \mathrm{c}$ ) GIXRD of 3 on $\mathrm{Si}(100), 9 \mathrm{~s}$ $\mathrm{NH}_{3}$ plasma pulse and same pulse sequence of 3 as shown in Table S1 at $220{ }^{\circ} \mathrm{C}$, showing crystalline hexagonal InN with a preferred orientation along the c-axis. The FWHM of the (002) peak was $0.660^{\circ}$.

Indium precursors 1-3 all rendered polycrystalline hexagonal $\mathrm{InN}$ films (Figure 3). The crystalline quality of the films, as manifested by the intensity of the XRD peaks, increased with decreasing size of the substituent on the endocyclic carbon atom of the ligand backbone. A smaller substituent on the endocyclic carbon in the ligand also turned the film growth to a more preferred orientation along the c-axis (Figure S3). This was seen by the higher intensity together with smaller FWHM of the (002) peak compared to the other XRD peaks in InN films from 3 compared to films from 2 . The 2 $\theta-\omega$ XRD (Figure S4) and GIXRD (Figure 3) measurement of $\mathbf{2}$ and $\mathbf{3}$ also indicates that some grains are titled indicative from the (002) peak being present in both measurements. The significant difference of crystallinity of $\mathbf{1}$, in comparison to $\mathbf{2}$ and 
3, can be attributed to the thermal instability of $\mathbf{1},{ }^{13}$ which made it difficult to grow thicker films than $\sim 10 \mathrm{~nm}$.

Top view SEM of the films deposited using 1 shows that the film is composed of grains with a significant size variation (Figure 4a). The size variation indicates that the smaller grains are nucleation points for the larger grains. This difference in size is an indication that the film grows in an island growth mode with continuous re-nucleation. Top-view SEM of films deposited using 2 shows a relatively rough film of large grains, with some grains merging to form bigger and more elongated crystalline grains (Figure 4b). Films deposited using 3 show smoother surface with a more coherent grain size (Figure 4c). The coherent grain size distribution indicates that no significant secondary nucleation occurs during growth. In contrast, $\mathbf{1}$ and $\mathbf{2}$ have grains with a larger distribution in shape and size, which is indicative of secondary nucleation during growth. ${ }^{27}$

Thus, the top view SEM, which indicates a more coherent grain size of InN film when the size of the substituent on the endocyclic carbon is reduced, is in line with the increased crystalline quality from XRD FWHM of the (002) peak. 
a)
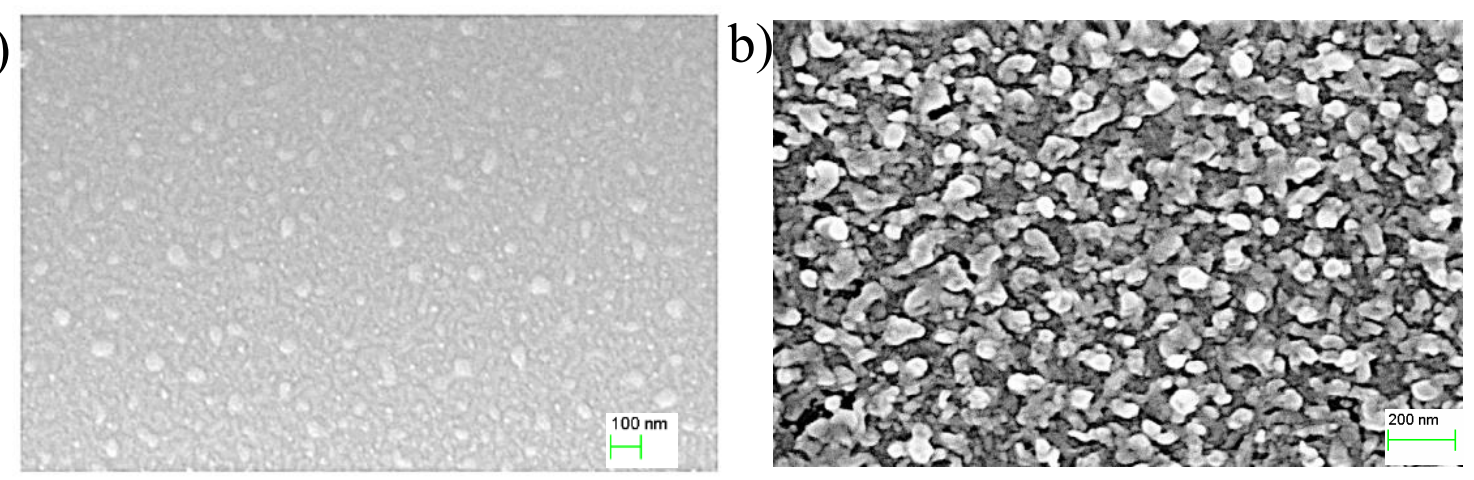

c)

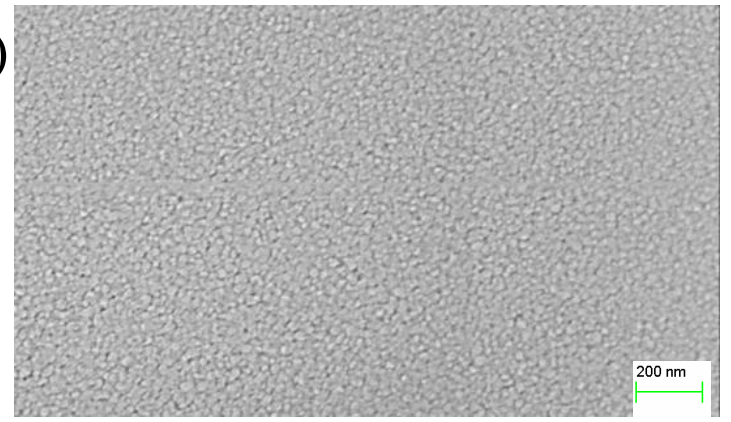

Figure 4. Top-view SEM of a) 1 with 4 s precursor pulse, $9 \mathrm{~s} \mathrm{NH}_{3}$ plasma at $\left.200^{\circ} \mathrm{C}, \mathrm{b}\right) 2$ with $5 \mathrm{~s}\left(5^{*}\right.$ and $1^{*}$ in Table S1) precursor pulse, $9 \mathrm{~s} \mathrm{NH}_{3}$ plasma pulse deposited at $300{ }^{\circ} \mathrm{C}$, c) 3 with 1 s precursor pulse, $9 \mathrm{~s} \mathrm{NH}_{3}$ pulse deposited at $220^{\circ} \mathrm{C}$.

\section{Chemical composition}

As described above, $\mathbf{1}$ is a poorly functioning In precursor for ALD of InN and only very thin films $(10 \mathrm{~nm})$ could be deposited. These films were difficult to analyse by XPS as sputter cleaning of the film surface was not possible. The In $3 \mathrm{~d}_{5} / 2$ was fitted with one In-N peak at $444.4 \mathrm{eV}$ and one In-O peak at $445.4 \mathrm{eV}^{28,29,30}$ (Figure S4). Since sputter cleaning of the film surface could not be performed, the bulk composition of the film could not be obtained. The surface contained 34 at. \% In, 27.6 at. \% N, 18.3 at. $\% \mathrm{O}$ and 20.1 at. $\% \mathrm{C}$, giving an $\mathrm{In} / \mathrm{N}=$ 1.23. Presumably, a significant portion of the oxygen and carbon content is due to air exposure prior to XPS analysis and remaining ligand on the surface.

XPS analysis of the bulk of InN films deposited using 2 shows 49.0 at. \% In, 45.4 at. \% N, 5.6 at. \% $\mathrm{O}$ and no carbon with an $\mathrm{In} / \mathrm{N}$ ratio of 1.08. High-resolution XPS spectrum was used to analyse the In $3 \mathrm{~d}_{5 / 2}$ and $\mathrm{N} 1 \mathrm{~s}$ regions of the InN films. The In $3 \mathrm{~d}_{5 / 2}$ region (Figure $5 \mathrm{a}$ ) could be fitted with peaks at $444.5 \mathrm{eV}$ and $445.6 \mathrm{eV}$, corresponding to In-N and In-O bonds, respectively. The N 1s region (Figure 5b) was fitted with peaks at $396.7 \mathrm{eV}$ and $397.7 \mathrm{eV}$, corresponding to $\mathrm{N}-\mathrm{In}$ and $\mathrm{N}-\mathrm{O}$ bonds, respectively. ${ }^{28,29,30}$ These results correlates well with previous studies that show a shift of $1 \mathrm{eV}$ between the $\mathrm{In}-\mathrm{N}$ and $\mathrm{In}-\mathrm{O}$ peaks of $\mathrm{InN} .^{28,29,30}$ 
In $3 \mathrm{~d}_{5 / 2} 2$
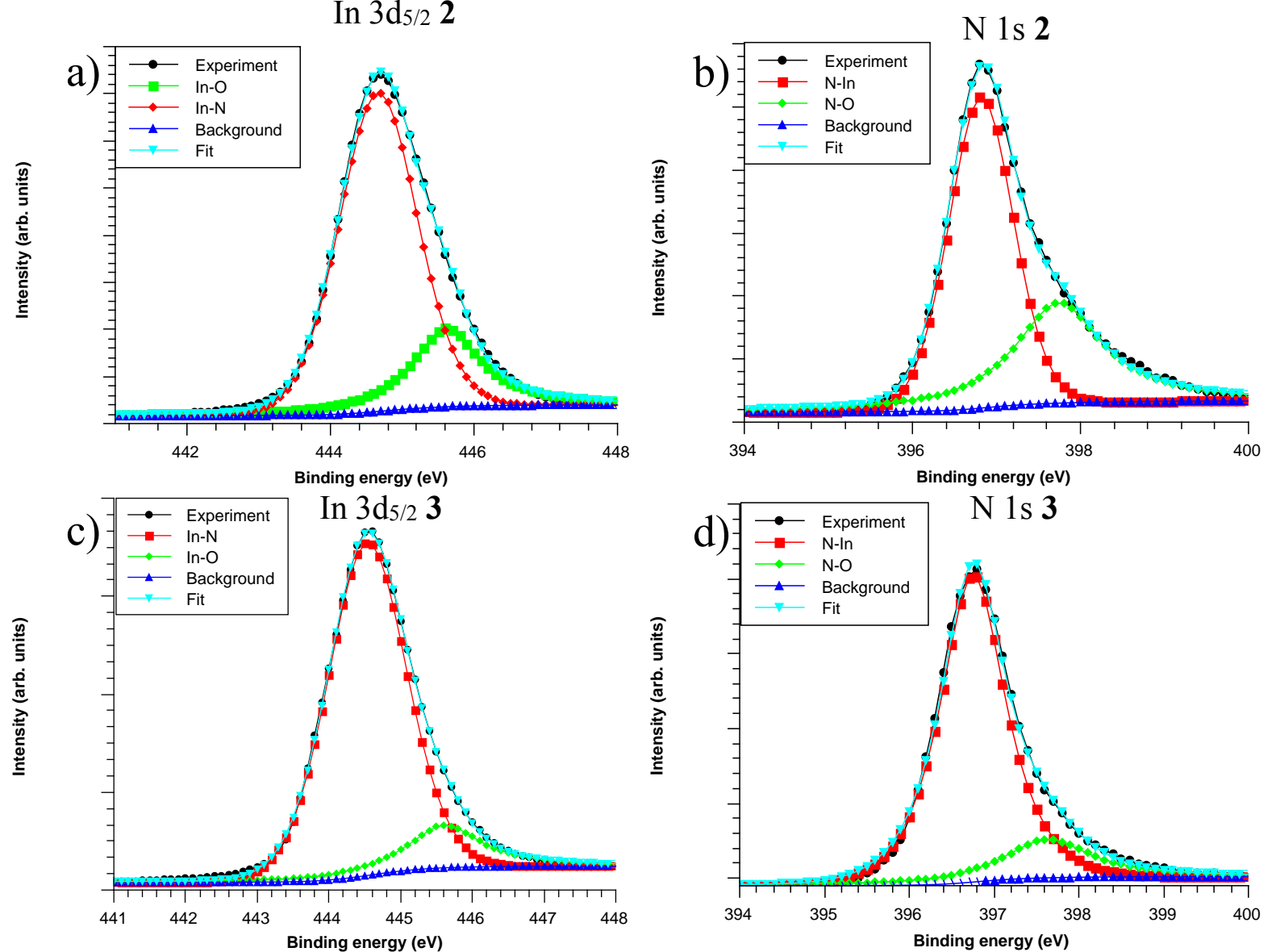

Figure 5. a) High resolution XPS spectra of In $3 d_{5 / 2}$ for 2 at $250^{\circ} \mathrm{C}, 9 \mathrm{~s} \mathrm{NH}_{3}$ plasma and the same pulse sequence of 2 as shown in Table S1. b) High resolution XPS spectra of $\mathrm{N} 1 \mathrm{~s}$ for 2 at $250{ }^{\circ} \mathrm{C}, 9 \mathrm{~s} \mathrm{NH}_{3}$ plasma and the same pulse sequence of 2 as shown in Table S1. c) High resolution XPS spectra of In $3 d_{5 / 2}$ for 3 at $220{ }^{\circ} \mathrm{C}, 9 \mathrm{~s} \mathrm{NH}_{3}$ plasma and the same pulse sequence of $\mathbf{3}$ as shown in Table S1. d) High resolution XPS spectra of N 1s for 3 at $250{ }^{\circ} \mathrm{C}, 9 \mathrm{~s} \mathrm{NH}_{3}$ plasma and the same pulse sequence of 3 as in Table S1. Two sub-peaks were assigned to obtain a good fit for both In $3 d_{5 / 2}$ and $N$ 1s. The two sub-peaks correspond to In-N and In-O bond.

XPS measurements of InN deposited from 3 after sputter cleaning shows that the films contain 49.1 at. $\% \mathrm{In}, 48.6$ at. $\% \mathrm{~N}, 2.3$ at. \% $\mathrm{O}$ and no carbon (Figure S5) with an $\mathrm{In} / \mathrm{N}$ of nearly 1 . The high resolution XPS spectrum of the In $3 \mathrm{~d}_{5} / 2$ region (Figure $5 \mathrm{c}$ ) was fitted with two sub-peaks; the major component at $444.5 \mathrm{eV}$ was assigned to $\mathrm{In}-\mathrm{N}$ bond and minor component at 445.6 $\mathrm{eV}$ assigned to In-O bond. Two sub-peaks were assigned to the high resolution XPS spectrum of the $\mathrm{N}$ 1s region (Figure 5d); 396.7 and $397.7 \mathrm{eV}$ peaks assigned to $\mathrm{N}-\mathrm{In}$ and $\mathrm{N}-\mathrm{O}$ bond, respectively. These values correlate well with the XPS measurements for $\mathbf{1}$ and $\mathbf{2}$, and with previous XPS measurements of $\mathrm{InN}^{28,29,30}$. As precursors 1-3 do not contain oxygen atoms, the source of the oxygen in the films is believed to be from air exposure of the reaction chamber upon loading the substrate, which is undertaken without a load lock, oxygen containing species formed in the quartz ICP tube during plasma discharge, the native silicon oxide on the substrate or oxidation of the InN upon exposure to air post deposition. Baking the reaction chamber and 
substrate etching by hydrogen plasma prior to deposition served to amend the air exposure upon loading substrates and native oxide on the silicon substrate. The $\mathrm{NH}_{3}$ plasma has previously been studied by optical emission spectroscopy and no optically active oxygen containing species where found. ${ }^{9}$ The significantly higher standard enthalpy of formation for $\operatorname{In}_{2} \mathrm{O}_{3}(-926$ $\mathrm{kJ} / \mathrm{mol})$ compared to that of $\mathrm{InN}(-138 \mathrm{~kJ} / \mathrm{mol})$ means that oxidation of $\mathrm{InN}$ upon air exposure is favoured. ${ }^{31}$ As the films are polycrystalline (Figure 4), oxygen diffusion into the grain boundaries is a likely process ${ }^{32}$ and thus air exposure post deposition is a possible cause for the oxygen levels in the InN films.

\section{Optical properties}

InN films from both 2 (deposited at $300{ }^{\circ} \mathrm{C}$ with $9 \mathrm{~s} \mathrm{NH}_{3}$ plasma pulse and same precursor pulse sequence as shown in Table S1) and $\mathbf{3}$ (deposited at $220{ }^{\circ} \mathrm{C}$ with $9 \mathrm{~s} \mathrm{NH}_{3}$ plasma pulse and same precursor pulse sequence as shown in Table S1) were analysed by Raman spectroscopy using a micro-Raman setup with $532 \mathrm{~nm}$ excitation. The spectra obtained are shown in Figure 6 together with a reference spectrum of the Si substrate. The Raman spectra of InN from $\mathbf{2}$ and $\mathbf{3}$ (denoted in the figure) shows the $\mathrm{A}_{1}(\mathrm{LO})$ band, which corresponds to wurtzite $\mathrm{InN}$ at approximately $586 \mathrm{~cm}^{-1} .{ }^{33}$ The $\mathrm{A}_{1}(\mathrm{LO})$ band is more distinct in sample 3 compared to sample 2, which is indicative of a better crystalline quality for films from this run and is in line with the results from XRD and SEM shown above. The position of the $A_{1}(\mathrm{LO})$ band in InN from 3 is close to its position in bulk $\mathrm{InN}\left(586 \mathrm{~cm}^{-1}\right)$, which shows in the spectrum after subtraction of the Si-substrate spectrum (Figure 6b). Conversely, in InN films from 2 the $\mathrm{A}_{1}(\mathrm{LO})$ band is substantially shifted towards lower wavenumbers of $\sim 580 \mathrm{~cm}^{-1}$. This shift indicates a higher tensile strain in the InN film from 2. The Raman spectra also show a gap mode at $375 \mathrm{~cm}^{-1}$, which has been attributed previously to In vacancies in the InN films. ${ }^{33}$ The gap mode is more pronounced in films from $\mathbf{2}$ in comparison to $\mathbf{3}$, which is consistent with the higher oxygen content in its films of $\mathbf{2}$ as observed by XPS analysis. A higher oxygen content would correlate to $\mathrm{N}-\mathrm{O}$ bonds, which explains the large In vacancies for $\mathbf{2}$ in contrast to $\mathbf{3}$. The major Raman peak at $521 \mathrm{~cm}^{-1}$ and the second order Raman band at $960 \mathrm{~cm}^{-1}$ correspond to the Si substrate. ${ }^{33}$ 

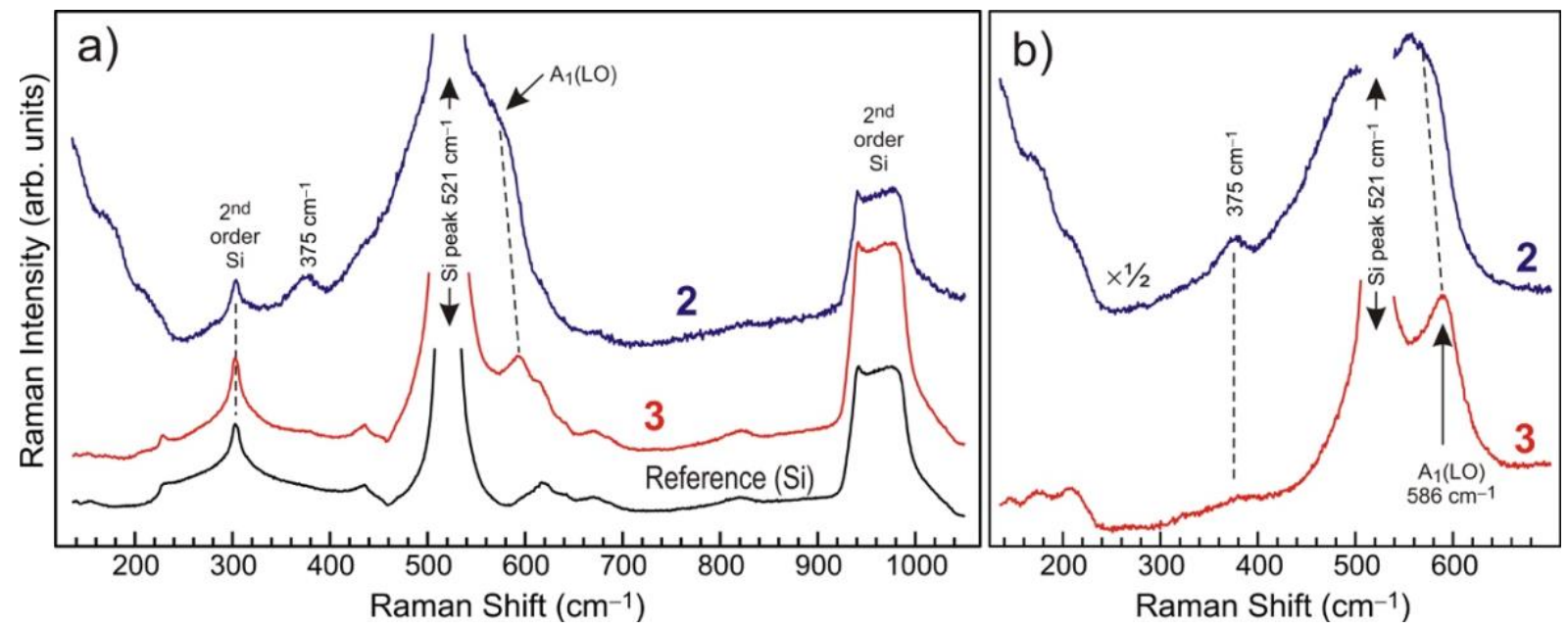

Figure 6. a) The Raman spectra of InN from 2 and 3, as indicated in the figure, together with the reference spectrum of the Si substrate provided for comparison (bottom curve). b) The spectra of the samples after subtraction of the substrate spectrum. For the purpose of subtraction, the spectra are normalized by the secondorder band of Si centered around $960 \mathrm{~cm}^{-1}$. This ensures nearly perfect subtractions of all second-order features of the Si spectrum from the spectrum of the samples with InN, but leads to either over-or under subtraction of the first-order Raman Si peak at $521 \mathrm{~cm}^{-1}$. The position of the $A_{l}(L O)$ mode is denoted, although this mode is apparently red-shifted to about $580 \mathrm{~cm}^{-1}$ compared to $586 \mathrm{~cm}^{-1}$ in unstrained wurtzite InN crystal. The gap mode at $375 \mathrm{~cm}^{-1}$ associated in with In vacancies is also denoted..$^{22}$ Note the scale change in the upper spectrum in panel $(b)$.

\section{Surface Chemistry}

Deposition of InN using this series of precursors revealed that smaller and less electron donating substituents on the endocyclic carbon $\left(\mathrm{NMe}_{2}<\mathrm{Me}<\mathrm{H}\right)$ not only leads to a more volatile and thermally stable precursor, but also an increase in film quality. Given that ALD is a surface chemistry-based deposition technique, the improved crystallinity and optical quality of the InN films deposited with $\mathbf{3}$, is most likely explained by an improved surface chemistry over $\mathbf{1}$ and 2. Lowering the bulk on the endocyclic carbon from a -Me to - H decreases the steric repulsion between the endocyclic substituent and the exocyclic $\mathrm{N}-i \operatorname{Pr}$ groups, allowing 3 to change its molecular geometry more easily. This would in-turn change the surface kinetics of 3, allowing it to react with the substrate faster as the bite angle of the ligand would be more acute and thus exposing the metal centre to the surface more upon chemisorption. This was observed when depositing $\mathrm{InN}$ with 3 , which required a total of $6 \mathrm{~s}$ over three consecutive pulses $(3,2,1 \mathrm{~s}$ pulse sequence) to saturate the surface. This time was substantially shorter than 1 and 2 , which required pulses totalling $11 \mathrm{~s}$ and $15 \mathrm{~s}$, respectively. An increase in surface kinetics for 3 over 2 was also observed in the ALD of $\operatorname{In}_{2} \mathrm{O}_{3} .{ }^{12} \mathrm{In}$ addition, as the $i \operatorname{Pr}$ groups can move away from each other more freely, this would make the deposited monolayer less hydrophobic, providing films that are more uniform with the absorbed precursor (Figure 7). This was shown for $\mathbf{3}$, which gave films with smoother morphology in comparison to $\mathbf{1}$ and $\mathbf{2}$. 
Moreover, the absorbed precursor would also have less steric repulsion with the surface, which would make the In-N bonds to the surface shorter, stronger and more thermally stable.

a)

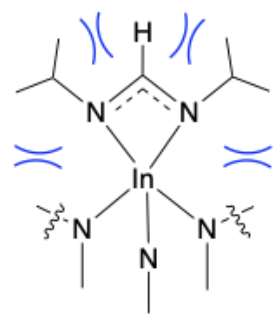

3 b)
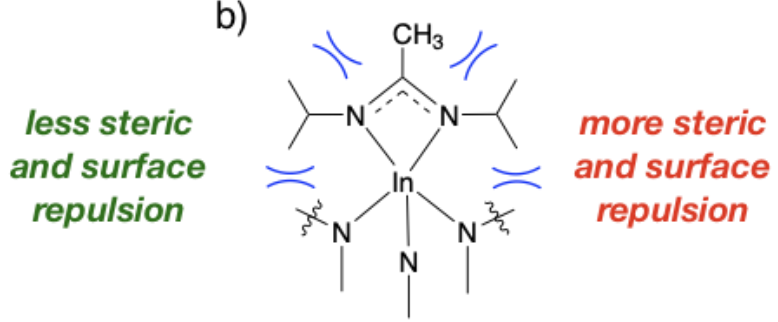

2

Figure 7. Schematics of the suggested improved surface chemistry for a) precursor 3, showing the decrease in steric and surface repulsion of its iPr groups in comparison to b) precursor 2. This model was originally proposed for $\mathrm{ALD}$ of $\mathrm{In}_{2} \mathrm{O}_{3}$ from 2 and $3{ }^{12}$

Depending on the endocyclic substituent's electron donating/withdrawing ability, the electronics of the ligand system would also be affected. This would change the $\mathrm{M}-\mathrm{N}$ bonding strength of the precursor, changing its reactivity with the surface and the reactivity of the formed monolayer towards the subsequent $\mathrm{NH}_{3}$ plasma pulse. This was observed in this InN study, as when the electron donating ability of the endocyclic substituent decreased $\left(\mathrm{NMe}_{2}>\mathrm{Me}>\mathrm{H}\right)$, the film quality increased

To further investigate the surface chemistry of these precursors, density functional theory (DFT) calculations were conducted. The bond dissociation enthalpy for precursors 1-3 were calculated and are shown in Table 1. The results show that $\mathbf{3}$ has lowest energy for removal of the ligands, reflecting its higher reactivity with the surface in contrast to $\mathbf{1}$ and $\mathbf{2}$. It was also observed for all precursors that the difference in energy required for losing the first two ligands $(67-75 \mathrm{~kJ} / \mathrm{mol})$ is approximately half that required to lose the third ligand $(126-141 \mathrm{~kJ} / \mathrm{mol})$. This result suggests that the precursor loses two ligands upon adsorption to give a surface of the mono-ligated In species (shown in Figure 7). Precursor 3 had the lowest energy required to remove the third ligand $(510 \mathrm{~kJ} / \mathrm{mol})$, showing that the nitidisation chemistry in the ALD process is more favored for $\mathbf{3}$ over $\mathbf{1}$ and $\mathbf{2}$.

As $i \operatorname{Pr}$ groups are known to undergo $\beta$-hydrogen elimination to the metal centre ${ }^{34}$, the electronic and steric properties would also affect the transfer reactivity of the methine proton $\left(\mathrm{CH}\left(\mathrm{CH}_{3}\right)_{2}\right.$ ) to the indium centre. To investigate this, the reaction free energy of $\beta$-hydrogen elimination was calculated for precursors 1-3 in the gas phase. The results show that the free energy for $\beta$ - 
hydrogen elimination was nearly double for $3(160 \mathrm{~kJ} / \mathrm{mol})$ than $\mathbf{1}(84 \mathrm{~kJ} / \mathrm{mol})$ and $2(99$ $\mathrm{kJ} / \mathrm{mol}$ ). This suggests that $\mathbf{1}$ and $\mathbf{2}$ are most likely to undergo $\beta$-hydrogen elimination than $\mathbf{3}$, which is consistent with its increased thermal stability. This also agrees with the electron donating ability of the endocyclic substituent, as a lower electron donating ability leads to a less stable hydride during the migration.

Table 1 . Bond dissociation enthalpy $(\mathrm{kJ} / \mathrm{mol})$ between the ligands and the In-metal centre

\begin{tabular}{cccc}
\hline Precursor & $1^{\text {st }}$ Ligand & $2^{\text {nd }}$ Ligand & $3^{\text {rd }}$ Ligand \\
\hline $\mathbf{1}$ & 337 & 412 & 538 \\
$\mathbf{2}$ & 327 & 394 & 535 \\
$\mathbf{3}$ & 312 & 382 & 510 \\
\hline
\end{tabular}

Finally, to investigate the deposited surface, the geometries of each ligand bonded to the In centre was calculated (Table 2). It should be noted that all mono-ligated precursor species are bonded to three nitrogen sites on the surface. The calculations show that all precursors have similar covalent bond lengths (In-N1; 1: $2.229 \AA$; 2: $2.259 \AA$; 3: $2.192 \AA$ ). However, precursor $\mathbf{3}$ shows an elongated coordination bond (2.802 $\AA$ ) in comparison to $\mathbf{1}(2.392 \AA)$ and $\mathbf{2}(2.408$ $\AA$ ). This allows the $i \operatorname{Pr}$ groups to fold up (3: C6-N1-C2: $118.80(9)^{\circ}$; C5-N4-C6: $\left.121.46(4)^{\circ}\right)$ and rotate more freely, decreasing their steric repulsion with other $i \operatorname{Pr}$ groups and the surface. The elongated coordination bond allows for the ligand of $\mathbf{3}$ to have a more acute bite angle $\left(53.08(0)^{\circ}\right)$ in contrast with $1\left(58.26(2)^{\circ}\right)$ and $2\left(57.06(8)^{\circ}\right)$. This in turn affects the covalent bond strength of the ligand (N1-In3) to the In centre for $3(159 \mathrm{~kJ} / \mathrm{mol})$ and was subsequently shown to be the weakest of the series. The lowest binding energy of the covalent bond and elongated coordination bond suggests the In centre is more exposed, making it easier to remove by the subsequent $\mathrm{NH}_{3}$ pulse. 
Table 2. Calculated geometries and bond strengths of mono-ligated In species on the surface

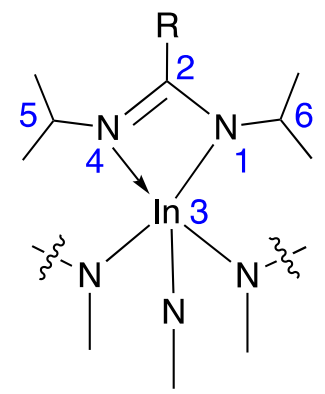

\begin{tabular}{ccccccc}
\hline Precursors & In3-N1 $(\AA)$ & In3-N4 $(\AA)$ & $\begin{array}{c}\text { Ligand } \\
\text { Bite }\end{array}$ & $\begin{array}{c}\text { Exocyclic } \\
\text { Angle 1 }\end{array}$ & $\begin{array}{c}\text { Exocyclic } \\
\text { Angle 2 }\end{array}$ & $\begin{array}{c}\text { In-L } \\
\text { Binding }\end{array}$ \\
& & & $\begin{array}{c}\text { Angle } \\
\text { N4-In3-N1 }\end{array}$ & C6-N1-C2 & C5-N4-C2 & Energy \\
& & & & & $(\mathrm{kJ} / \mathrm{mol})$ \\
\hline $\mathbf{1}$ & 2.229 & 2.392 & $58.26(2)$ & $123.87(9)$ & $126.00(0)$ & 188 \\
$\mathbf{2}$ & 2.259 & 2.408 & $57.06(8)$ & $123.37(1)$ & $127.04(9)$ & 176 \\
$\mathbf{3}$ & 2.192 & 2.802 & $53.08(0)$ & $118.80(9)$ & $121.46(4)$ & 159 \\
\hline
\end{tabular}

Finally, as $i \operatorname{Pr}$ groups are known to undergo $\beta$-hydrogen elimination to the metal centre, the electronic and steric properties would also affect the transfer reactivity of the methine proton $\left(\mathrm{CH}\left(\mathrm{CH}_{3}\right)_{2}\right)$ to the indium centre. ${ }^{34}$ To investigate this, the reaction free energy of $\beta$-hydrogen elimination was calculated for all precursors. The results show that the free energy for $\beta$ hydrogen elimination was lowest for $1(84 \mathrm{~kJ} / \mathrm{mol})$, followed by $2(99 \mathrm{~kJ} / \mathrm{mol})$ and was highest for $3(160 \mathrm{~kJ} / \mathrm{mol})$. This suggests that $\mathbf{1}$ is most likely to undergo $\beta$-hydrogen elimination while $\mathbf{3}$ is less likely. This agrees with the electron donating ability of the endocyclic substituent, as a lower electron donating ability leads to a less stable hydride during the migration. 


\section{Summary and Conclusion}

The homoleptic hexacoordinated guanidinate and amidinate precursors 1-3 were investigated as possible In precursors for ALD of $\mathrm{InN}$ with $\mathrm{NH}_{3}$ plasma. All three precursors rendered crystalline InN films on $\mathrm{Si}(100)$ with differing quality. The film composition by XPS showed a In/ $\mathrm{N}$ ratio close to 1 when using 3. The oxygen content was 5.6 at. $\%$ for 2 and 2.3 at. $\%$ for 3, whilst the films had no detectable carbon impurities by XPS. The films grown with all three precursors showed a dominating $\mathrm{In}-\mathrm{N}$ bond in the $\mathrm{In} 3 \mathrm{~d}_{5 / 2}$ and $\mathrm{N} 1 \mathrm{~s}$ high-resolution XPS. Raman spectroscopy showed the wurtzite $\operatorname{InN} A_{1}(\mathrm{LO})$ band in films from $\mathbf{2}$ and $\mathbf{3}$, with a smaller peak shift in InN from 3 compared to bulk InN. The thermal stability and volatility of the precursors has previously been shown to increase with decreasing size of the substituent on the endocyclic carbon position of the ligand backbone, from $-\mathrm{NMe}_{2}(\mathbf{1})$, to $-\mathrm{Me}(\mathbf{2})$, to $-\mathrm{H}(\mathbf{3})$. We show that the size of the substituent also affects the quality of the deposited InN films as the crystallinity, morphology, In/N ratio and optical properties were improved with the decreasing size of the substituent. We show by quantum chemical modelling that a smaller substituent renders less steric hindrance on the surface allowing a weaker bond between ligand and In centre. We suggest that the lower steric hindrance and weaker bonded ligand can explain the improved film properties and ALD process with smaller substituents.

\section{Acknowledgements}

This project was founded by the Swedish foundation for Strategic Research through the project "Time-resolved low temperature CVD for III-nitrides" (SSF-RMA 15-0018) and by the Knut and Alice Wallenberg foundation through the project "Bridging the THz gap" (No. KAW 2013.0049). L.O. acknowledges financial support from the Swedish Government Strategic Research Area in Materials Science on Functional Materials at Linköping University (Faculty Grant SFO Mat LiU no. 2009 00971). Supercomputing resources were provided by the Swedish National Infrastructure for Computing (SNIC) and the Swedish National Supercomputer Centre (NSC). 


\section{References}

(1) Bhuiyan, A. G.; Hashimoto, A.; Yamamoto, A. Indium Nitride (InN): A Review on Growth, Characterization, and Properties. J. Appl. Phys. 2003, 94 (5), 2779-2808.

(2) Bellotti, E.; Doshi, B. K.; Brennan, K. F.; Albrecht, J. D.; Ruden, P. P. Ensemble Monte Carlo Study of Electron Transport in Wurtzite InN. J. Appl. Phys. 1999, 85 (2),

(3) Butcher, K. S. A.; Tansley, T. L. InN, Latest Development and a Review of the BandGap Controversy. Superlattices Microstruct. 2005, 38 (1), 1-37.

(4) Ivanov, S. V.; Shubina, T. V.; Komissarova, T. A.; Jmerik, V. N. Metastable Nature of InN and In-Rich InGaN Alloys. J. Cryst. Growth 2014, 403, 83-89.

(5) Ruffenach, S.; Moret, M.; Briot, O.; Gil, B. Recent Advances in the MOVPE Growth of Indium Nitride. Phys. Status Solidi Appl. Mater. Sci. 2010, 207 (1), 9-18.

(6) Rönnby, K.; Buttera, S. C.; Rouf, P.; Barry, S. T.; Ojamäe, L.; Pedersen, H. Methylamines as Nitrogen Precursors in Chemical Vapor Deposition of Gallium Nitride. J. Phys. Chem. C 2019, 123 (11), 6701-6710.

(7) Nepal, N.; Mahadik, N. A.; Nyakiti, L. O.; Qadri, S. B.; Mehl, M. J.; Hite, J. K.; Eddy, C. R. Epitaxial Growth of Cubic and Hexagonal InN Thin Films via Plasma-Assisted Atomic Layer Epitaxy. Cryst. Growth Des. 2013, 13 (4), 1485-1490.

(8) Haider, A.; Kizir, S.; Biyikli, N. Low-Temperature Self-Limiting Atomic Layer Deposition of Wurtzite InN on Si(100). AIP Adv. 2016, 6 (4).

(9) Deminskyi, P.; Rouf, P.; Ivanov, I. G.; Pedersen, H. Atomic Layer Deposition of InN Using Trimethylindium and Ammonia Plasma. J. Vac. Sci. Technol. A 2019, 37 (2), 020926.

(10) Buttera, S. C.; Mandia, D. J.; Barry, S. T. Tris(Dimethylamido)Aluminum(III): An Overlooked Atomic Layer Deposition Precursor. J. Vac. Sci. Technol. A Vacuum, Surfaces, Film. 2016, 35 (1), 01B128.

(11) Gebhard, M.; Hellwig, M.; Parala, H.; Xu, K.; Winter, M.; Devi, A. Indium-TrisGuanidinates: A Promising Class of Precursors for Water Assisted Atomic Layer Deposition of In2O3 Thin Films. Dalt. Trans. 2014, 43 (3), 937-940.

(12) Kim, S. B.; Jayaraman, A.; Chua, D.; Davis, L. M.; Zheng, S. L.; Zhao, X.; Lee, S.; Gordon, R. G. Obtaining a Low and Wide Atomic Layer Deposition Window (150-275 ${ }^{\circ} \mathrm{C}$ ) for $\mathrm{In}_{2} \mathrm{O}_{3}$ Films Using an In III Amidinate and $\mathrm{H}_{2} \mathrm{O}$. Chem. - A Eur. J. 2018, 24 (38), 9525-9529.

(13) Gebhard, M.; Hellwig, M.; Kroll, A.; Rogalla, D.; Winter, M.; Mallick, B.; Ludwig, A.; Wiesing, M.; Wieck, A. D.; Grundmeier, G.; et al. New Amidinate Complexes of Indium(III): Promising CVD Precursors for Transparent and Conductive In2O3 Thin Films. Dalt. Trans. 2017, 46 (31), 10220-10231.

(14) Buttera, S. C.; Rönnby, K.; Pedersen, H.; Ojamäe, L.; Barry, S. T. Thermal Study of an Indium Trisguanidinate as a Possible Indium Nitride Precursor. J. Vac. Sci. Technol. A Vacuum, Surfaces, Film. 2018, 36 (1), 01A101.

(15) McCarthy, R. F.; Weimer, M. S.; Emery, J. D.; Hock, A. S.; Martinson, A. B. F. Oxygen-Free Atomic Layer Deposition of Indium Sulfide. ACS Appl. Mater. Interfaces 2014, 6 (15), 12137-12145.

(16) Frisch, M. J.; Trucks, G. W.; Schlegel, H. B.; Scuseria, G. E.; Robb, M. A.; Cheeseman, J. R.; Scalmani, G.; Barone, V.; Petersson, G. A.; Nakatsuji, H.; et al. Gaussian 16, Revision B.01. Gaussian, Inc: Wallingford CT 2016.

(17) Becke, A. D. Density-Functional Thermochemistry. III. The Role of Exact Exchange. 
J. Chem. Phys. 1993, 98 (7), 5648-5652.

(18) Lee, C.; Yang, W.; Parr, G. R. Development of the Colle-Salvetti Correlation-Energy Formula into a Functional of the Electron Density. Phys. Rev. B - Condens. Matter Mater. Phys. 1988, 37 (2), 785-789.

(19) Grimme, S.; Antony, J.; Ehrlich, S.; Krieg, H. A Consistent and Accurate Ab Initio Parametrization of Density Functional Dispersion Correction (DFT-D) for the 94 Elements H-Pu. J. Chem. Phys. 2010, 132 (15).

(20) Kresse, G.; Furthmiiller, J. Efficiency of Ab-Initio Total Energy Calculations for Metals and Semiconductors Using a Plane-Wave Basis Set. Comput. Mater. Sci. 1966, $6,15-50$.

(21) Kresse, G.; Furthmüller, J. Efficient Iterative Schemes for Ab Initio Total-Energy Calculations Using a Plane-Wave Basis Set. Phys. Rev. B - Condens. Matter Mater. Phys. 1996, 54 (16), 11169-11186.

(22) Sheppard, D.; Terrell, R.; Henkelman, G. Optimization Methods for Finding Minimum Energy Paths. J. Chem. Phys. 2008, 128 (13).

(23) Perdew, J. P.; Burke, K.; Ernzerhof, M. Perdew, Burke, Ernzerhof - 1997 - Generalized Gradient Approximation Made Simple(2). Phys. Rev. Lett. 1996, 77, 3865-3868.

(24) Perdew, J. P.; Burke, K.; Ernzerhof, M. Erratum: Generalized Gradient Approximation Made Simple (Physical Review Letters (1996) 77 (3865)). Physical Review Letters. Gaussian, Inc: Wallingford CT 1997, p 1396.

(25) Kresse, G.; Joubert, D. Kresse, Joubert - Unknown - From Ultrasoft Pseudopotentials to the Projector Augmented-Wave Method. Phys. Rev. B - Condens. Matter Mater. Phys. 1999, 59 (3), 1758-1775.

(26) Shiraishi, K. A New Slab Model Approach for Electronic Structure Calculation of Polar Semiconductor Surface. J. Phys. Soc. Japan 1990, 59 (10), 3455.3458.

(27) Reichelt, K. Nucleation and Growth of Thin Films. Vacuum 1988, 38 (12), 1083-1099.

(28) Veal, T. D.; King, P. D. C.; Jefferson, P. H.; Piper, L. F. J.; McConville, C. F.; Lu, H.; Schaff, W. J.; Anderson, P. A.; Durbin, S. M.; Muto, D.; et al. In Adlayers on c -Plane InN Surfaces: A Polarity-Dependent Study by x-Ray Photoemission Spectroscopy. Phys. Rev. B - Condens. Matter Mater. Phys. 2007, 76 (7), 1-8.

(29) Wu, C. L.; Lee, H. M.; Kuo, C. T.; Chen, C. H.; Gwo, S. Absence of Fermi-Level Pinning at Cleaved Nonpolar InN Surfaces. Phys. Rev. Lett. 2008, 101 (10), 3-6.

(30) Nagata, T.; Koblmüller, G.; Bierwagen, O.; Gallinat, C. S.; Speck, J. S. Surface Structure and Chemical States of A-Plane and c-Plane InN Films. Appl. Phys. Lett. 2009, 95 (13), 1-4.

(31) CRC Handbook of Chemistry and Physics, 85:th ed.; Lide, R. D., Ed.; CRC Press: Boca Raton, Florida, 2018.

(32) Callister, W. D. Materials Science and Engineering 8th Edition ISV with WileyPLUS Set, 8th ed.; John Wiley \& Sons: Chichester, 2010.

(33) Wang, J. B.; Li, Z. F.; Chen, P. P.; Lu, W.; Yao, T. Raman Study of Gap Mode and Lattice Disorder Effect in InN Films Prepared by Plasma-Assisted Molecular Beam Epitaxy. Acta Mater. 2007, 55 (1), 183-187.

(34) Barry, S. T. Amidinates, Guanidinates and Iminopyrrolidinates: Understanding Precursor Thermolysis to Design a Better Ligand. Coord. Chem. Rev. 2013, 257 (2324), 3192-3201. 


\section{The endocyclic carbon substituent of guanidinate and amidinate precursors controlling ALD of InN films}

Polla Rouf*, Nathan J. O’Brien, Karl Rönnby, Rouzbeh Samii, Ivan G. Ivanov, Lars Ojamäe, Henrik Pedersen

Department of Physics, Chemistry and Biology, Linköping University, SE-581 83 Linköping, Sweden

*Corresponding author, e-mail: polla.rouf@liu.se 
Table S1. Pulse, purge and flow parameters used for 1, 2 and 3.

\begin{tabular}{|l|l|l|l|l|l|l|l|l|}
\hline \multicolumn{3}{|c|}{1} & \multicolumn{3}{c|}{ 2 } & \multicolumn{3}{c|}{3} \\
\hline $\begin{array}{l}\text { Pulse } \\
(\mathbf{s})\end{array}$ & $\begin{array}{l}\text { Purge } \\
(\mathbf{s})\end{array}$ & $\begin{array}{l}\text { Flow } \\
(\mathbf{s c c m})\end{array}$ & $\begin{array}{l}\text { Pulse } \\
(\mathbf{s})\end{array}$ & $\begin{array}{l}\text { Purge } \\
(\mathbf{s})\end{array}$ & $\begin{array}{l}\text { Flow } \\
(\mathbf{s c c m})\end{array}$ & $\begin{array}{l}\text { Pulse } \\
(\mathbf{s})\end{array}$ & $\begin{array}{l}\text { Purge } \\
(\mathbf{s})\end{array}$ & $\begin{array}{l}\text { Flow } \\
(\mathbf{s c c m})\end{array}$ \\
\hline 5 & 0.1 & 500 & 5 & 6 & 500 & 3 & 5 & 100 \\
\hline $6^{*}$ & 10 & 90 & 4 & 3 & 400 & 2 & 7 & 90 \\
\hline & & & 3 & 4 & 300 & $1 *$ & 10 & 90 \\
\hline & & 2 & 5 & 200 & & & \\
\cline { 3 - 7 } & & $1 *$ & 6 & 100 & & & \\
\hline
\end{tabular}

* indicates the pulses that was varied in order to obtain a saturation curve.
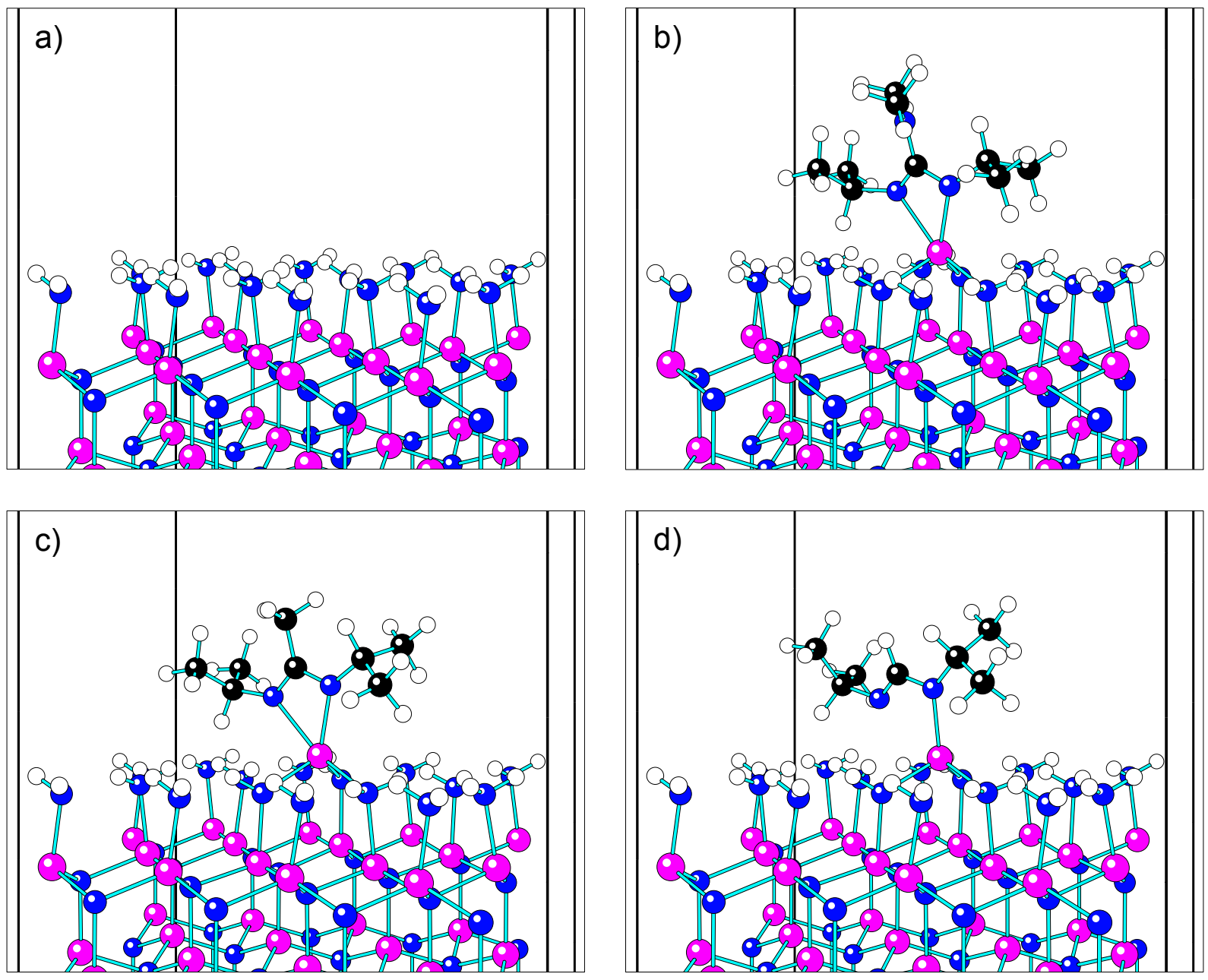

Figure S1. Surfaces obtained after optimization. a) Model $\mathrm{NH}_{2}$ surface, b) adsorbed 1, c) adsorbed 2 and d) adsorbed 3. 


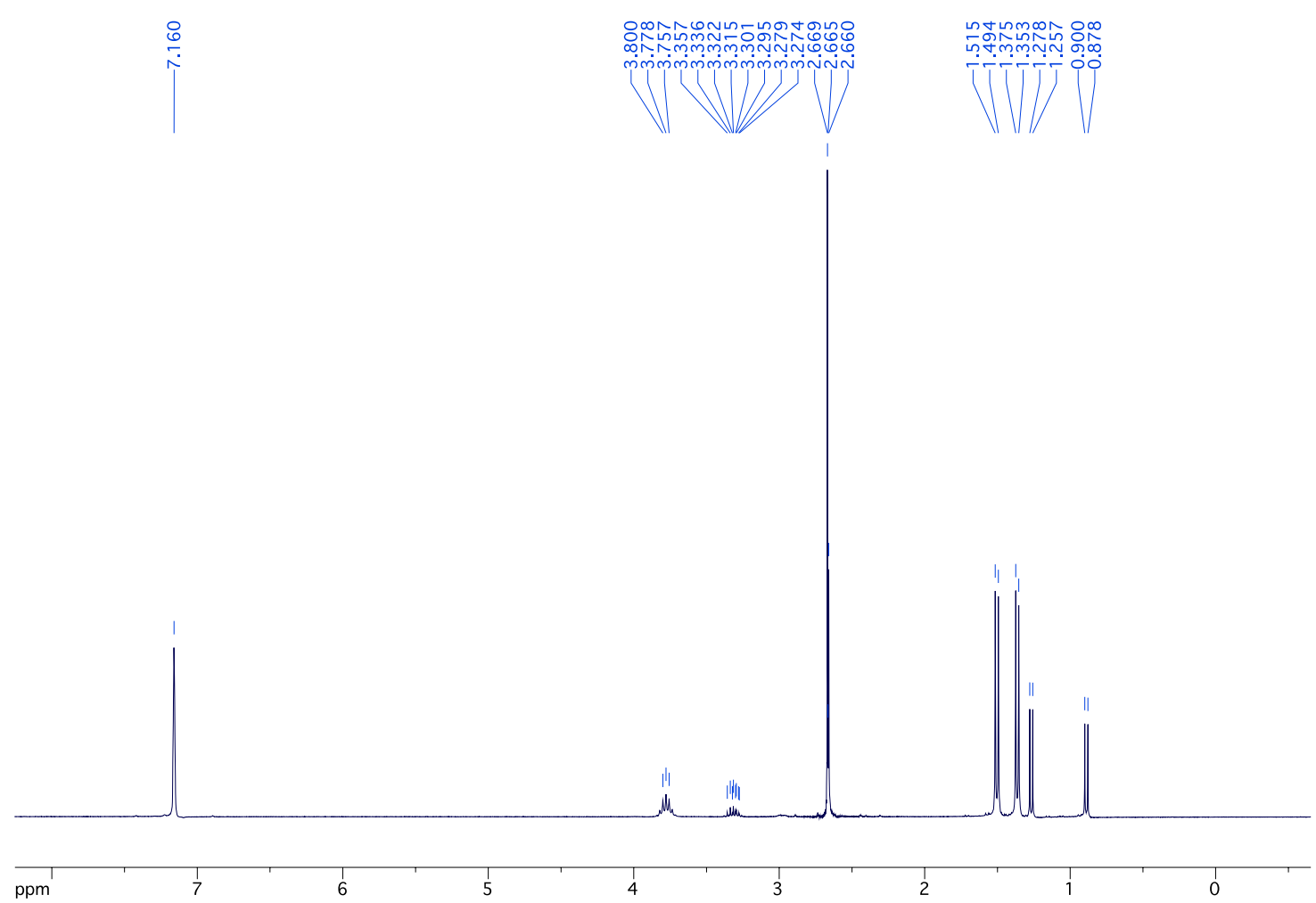

Figure S2. The ${ }^{1} H$-NMR spectrum of the grey powder left in the bubbler after deposition with 3. The powder was dissolved in $C_{6} D_{6}$.

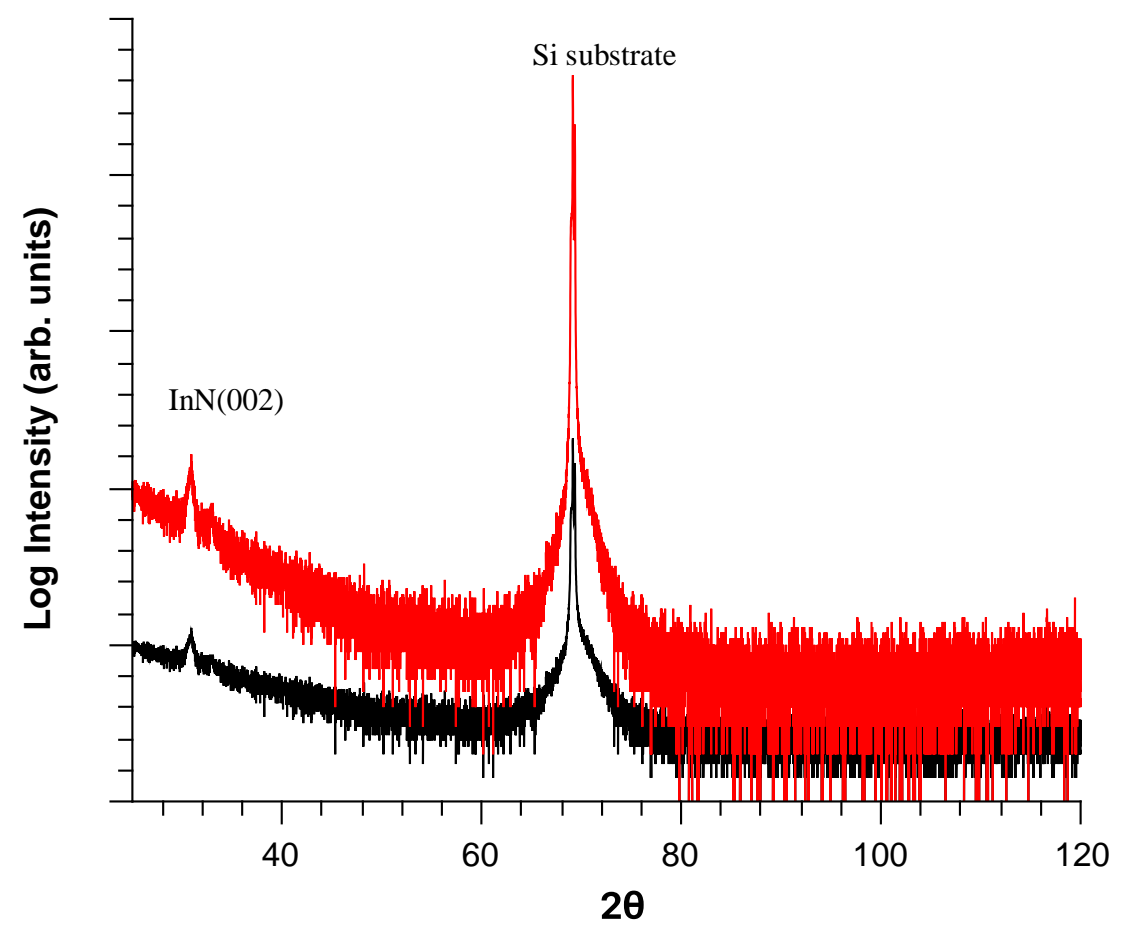

Figure S3. The 2 $\theta-\omega X R D$ of 2, same pulse sequence as Table S1, 9s $\mathrm{NH}_{3}$ plasma pulse deposited at $300{ }^{\circ} \mathrm{C}$ (black) and 3 same pulse sequence as Table S1, 9s $\mathrm{NH}_{3}$ plasma pulse deposited at $220{ }^{\circ} \mathrm{C}$ (red). Both showing hexagonal InN (002) peak, larger intensity for 3 compared to 2, indicating a preferred growth along the c-axis. 

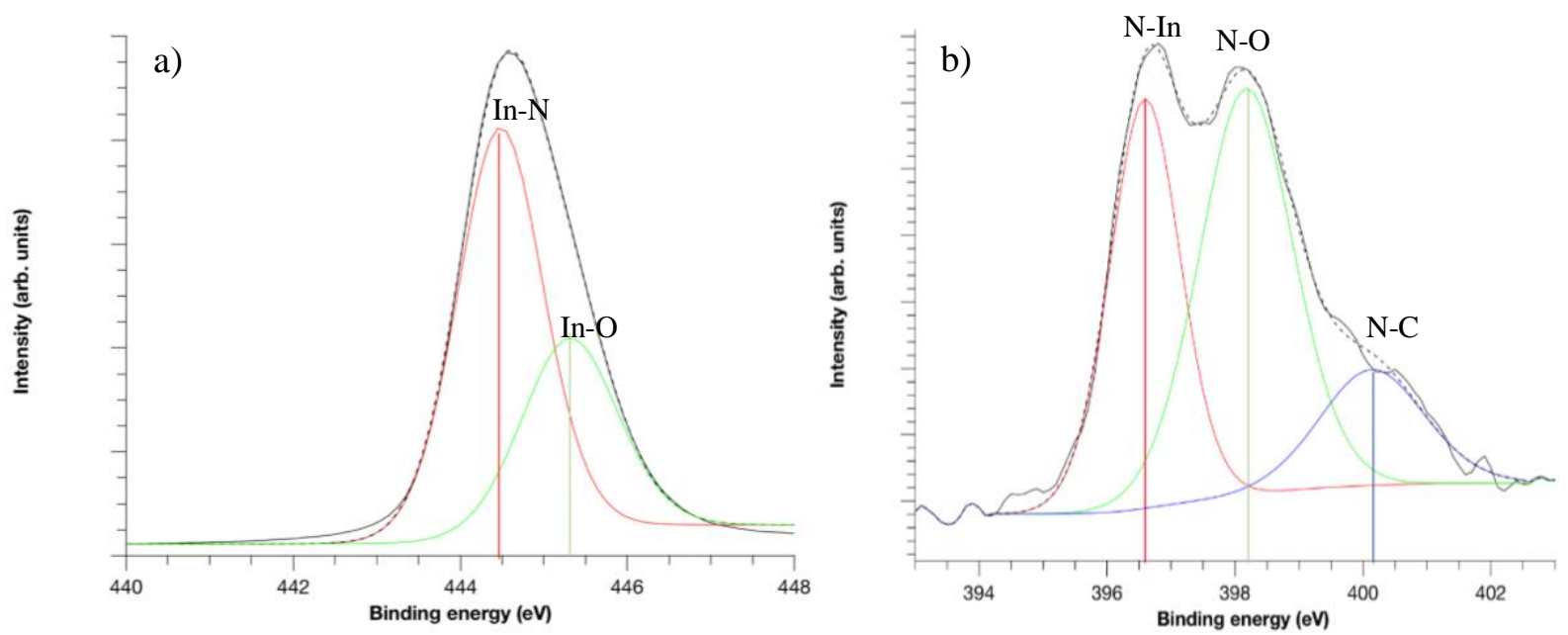

Figure S4: The high-resolution XPS scan for In $3 d_{5 / 2}$ (a) and N $1 s$ (b) of an InN film deposited using 1, same pulse sequence as Table S1, $13 \mathrm{~s} \mathrm{NH}_{3}$ plasma pulse deposited at $200{ }^{\circ} \mathrm{C}$. Due to the low thickness of the film, the spectra are recorded without sputter cleaning the film surface.
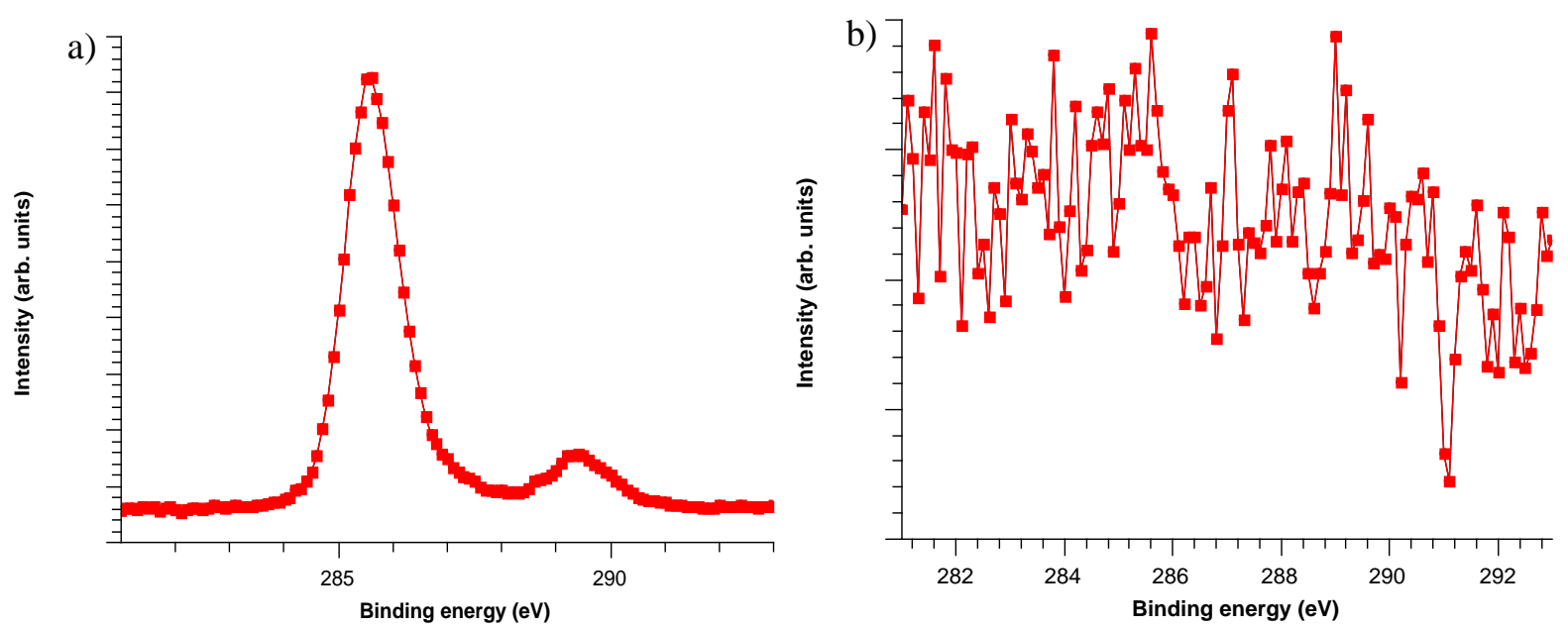

Figure S5. The high-resolution scan of C 1 s for 3 using same pulse sequence as in Table S1 with 9s $\mathrm{NH}_{3}$ plasma pulse deposited at $220{ }^{\circ} \mathrm{C}$, where a) shows the spectra before and b) after sputtering. 
